\title{
Alumnado de origen latinoamericano en Cataluña: un análisis de su volumen y resultados escolares ${ }^{1}$
}

\author{
Jordi BaYona-I-CarRasco ${ }^{2}$ | ANDREu Domingo 3 \\ Recibido: 04/04/2019 | Aceptado: 23/10/2019
}

\section{Resumen}

La mayor parte del alumnado de origen latinoamericano en las escuelas catalanas queda invisibilizado estadísticamente debido al peso creciente de las nacionalizaciones y de las segundas generaciones. Gracias a disponer de los microdatos del curso 2015-2016 cedidos por el Departament d'Ensenyament y al cruce de estos registros con el Padrón Continuo de población se ha podido analizar la trayectoria migratoria de los alumnos en relación a sus resultados escolares, creando una tipología generacional. Este análisis se realiza para los estudiantes de origen latinoamericano, con el objetivo de conocer sus principales características sociodemográficas y su desempeño escolar, medido a partir de las tasas de idoneidad y de la obtención del graduado de ESO. Además del conjunto de estudiantes de origen latinoamericano se estudian cinco orígenes en concreto (Honduras, Bolivia, República Dominicana, Argentina y Ecuador), que se caracterizan por una importante presencia en Cataluña pero con calendarios muy distintos en su llegada a España, así como en sus perfiles sociodemográficos y en su incorporación a la escuela. Los resultados obtenidos indican el creciente peso de los descendientes de inmigrados en las escuelas, y unos rendimientos escolares que se ven fuertemente perturbados por el proceso migratorio.

Palabras clave: inmigración, escuela, éxito escolar, perspectiva generacional, latinoamericanos

\section{Abstract \\ Students with Latin-American origin in Catalonia: an analysis of their volume and school results}

Most of the students of Latin American origin in Catalan schools are invisible statistically due to the growing weight of nationalizations and second generations. 2015-2016 students' microdata has been connected with the Population Register. With this data we have constructed a generational typology to analyze the migratory trajectory of the students in relation to their school achievement. This analysis has been conducted for Latin American students, with the main aim of knowing their sociodemographic characteristics and their school performance, measured from a suitability rate and the obtention of compulsory studies. In addition to the Latin American group, five origins has been studied (Honduras, Bolivia, the Dominican Republic, Argentina and Ecuador), all of them characterized by an important presence in Catalonia but with very different calendars on their arrival in Spain, as well as in their sociodemographic profiles and in his

\footnotetext{
1. Este trabajo se enmarca en el proyecto de I+D dirigido por Andreu Domingo "Demografía, migraciones y nuevas fronteras estadísticas: Big Data, Registros continuos de población y Registros administrativos” (CSO2017-85670-R).

2. Profesor Serra Húnter, Dep. Geografía, Universitat de Barcelona y Centre d'Estudis Demogràfics/CERCA. jordibayona@ub.edu

3. Centre d'Estudis Demogràfics/CERCA. adomingo@ced.uab.es
} 
incorporation into the school. Results obtained from this study indicates the increasing weight of the immigrants' descendants in schools, and a school performance that is strongly disturbed by the migratory process.

Key words: Immigration, school, school success, generational perspective, Latin-American

\section{Introducción}

La inmigración latinoamericana, a partir del boom migratorio internacional de inicios de siglo XXI, ha sido la protagonista principal del crecimiento de la inmigración extranjera en España (Izquierdo et al. 2002; Domingo, 2005; Hierro, 2013; Bayona et al. 2018), también en Cataluña. En este último caso, que centra nuestra atención, los inmigrantes de origen latinoamericano llegan a representar alrededor del $40 \%$ de la población inmigrada residente, a pesar de la elevada diversidad de orígenes en los flujos llegados durante los últimos años (Galeano et al. 2016). Los datos estadísticos más recientes, de inicios de 2018, indican como la cifra de nacidos en Latinoamérica y residentes en Cataluña asciende a 588.941 personas, el 40,5\% de los inmigrados empadronados y hasta un $7,4 \%$ de la población total, dato que es producto de una dinámica migratoria de nuevo ascendente y que significa un máximo histórico.

En el caso de España, la población latinoamericana ha sido discriminada positivamente, en lo jurídico en el acceso a la nacionalidad preferencial, junto con otras antiguas colonias españolas a las que se demanda dos años de residencia continuada en situación regular, frente a los 10 años exigidos al resto (Domingo y Ortega, 2015), pero también en la preferencia declarada por la población española respecto a otros orígenes contrastada a lo largo del tiempo mediante encuestas de opinión (Izquierdo et al. 2002; Díez Nicolás, 2005), así como indirectamente y de forma opaca por las políticas de control de fronteras aplicadas por diferentes gobiernos en España (Vono, 2010; Domingo, 2018). A esa preferencia tenemos que añadir el capital humano que efectivamente significa la lengua e historia compartidas que, redundaría en una más rápida integración también en el caso del alumnado, y por lo tanto de mejores resultados respecto al resto de menores inmigrados.

Uno de los ámbitos donde la repercusión de la inmigración internacional ha sido más importante es el de la escuela. El progresivo crecimiento del número de estudiantes, muchos de ellos incorporados a medio curso en los años de mayor intensidad migratoria, ha sido seguido con atención (Cachón, 2003; Carrasco, 2003; Vila, 2006; Capote y Nieto, 2017), especialmente en lugares como Cataluña donde la llegada de menores inmigrantes a la escuela se produjo ya en los años noventa y con una progresiva intensidad (Palaudàries, 2002; Albaigés y Ferrer-Esteban, 2017). La llegada de menores junto a sus progenitores, o vía reagrupación familiar, fueron las situaciones más usuales durante los primeros años. Actualmente, con la antigüedad alcanzada de los primeros flujos, la situación se caracteriza por el crecimiento de las segundas generaciones, descendientes de los inmigrados y nacidos ya en Cataluña. Si la primera acogida y la creciente diversidad son aspectos iniciales de atención (Palaudàries, 2002), más adelante el foco se desplaza hacia procesos como la segregación escolar y los resultados alcanzados, en particular las elevadas tasas de "fracaso escolar" que sufre el alumnado de nacionalidad extranjera (Besalú, 2002; Huguet y Navarro 2006; García Castaño et al. 2008; Bonal et al. 2015; Bayona y Domingo, 2018a; Bonal y Bellei, 2018), o incluso más recientemente sobre los resultados de las segundas generaciones (Aparicio y Portes, 2014; Portes et al., 2016; Domingo y Bayona, 2019; Bayona et al. 2020). 
En relación a este último aspecto, el rendimiento escolar del alumnado de origen inmigrante es normalmente menor que el resto de alumnos (OCDE, 2016), según se desprende de los datos del informe PISA. Cuando se intenta explicar esta diferenciación, autores como Schnepf (2007) indican como el menor rendimiento escolar se debe principalmente a dos factores, o bien por un menor capital cultural de las familias de estos menores (en comparación con los autóctonos), o bien por una mayor concentración de estudiantes de origen inmigrante en la escuela. Además, factores propios del proceso migratorio como el año de llegada adquieren gran importancia, encontrándose un menor rendimiento entre los llegados de forma más reciente (Böhlmark, 2008). En cambio, y en el caso de los latinoamericanos, otro de los factores a tener en cuenta como es el desconocimiento de la lengua (Corak, 2011) adquiriría menor importancia. En cuanto a la concentración, el efecto en España es generalmente de poca magnitud, a excepción de cuando se superan umbrales de concentración elevados ${ }^{4}$ (Cebolla-Boado y Garrido, 2011; Bayona y Domingo, 2019). En cambio, la segregación escolar se situaría entre las más elevadas a escala europea (Murillo y Martínez-Garrido, 2018). La selección inicial de la escuela por parte de los progenitores es según el informe del Síndic de Greuges (2016) una de las principales causas de esta segregación escolar en Cataluña, tanto entre escuela pública y privada-concertada como dentro de los centros de titularidad pública. Así, la escuela pública, que virtualmente se presenta como un mecanismo indirecto de redistribución social, en la práctica acabaría actuando como uno de los dispositivos de reproducción de las desigualdades sociales (Bourdieu, 1998).

En este contexto, el presente artículo tiene tres grandes objetivos, centrados todos ellos en la presencia de estudiantes de origen latinoamericano dentro del sistema educativo en Cataluña. El primero es precisamente su cuantificación, que se realiza a través de una tipología generacional a partir de los datos escolares y de su enlace con el Padrón continuo de población, visibilizando los descendientes de la inmigración de origen latinoamericano. El segundo es el análisis de su incorporación a la escuela, teniendo en cuenta las distintas etapas y cursos educativos, para en último lugar estudiar el éxito (o fracaso) escolar, que se realizará a partir de la observación de las tasas de idoneidad y de la obtención del grado de ESO, entendiendo que la no obtención del título que acredita los estudios mínimos obligatorios puede representar una losa para la integración social futura de estos menores.

\section{Datos estadísticos y metodología}

Los datos empleados en este trabajo provienen del cruce de registros efectuado por el Institut d'Estadística de Catalunya (Idescat) entre los microdatos del alumnado matriculado en enseñanzas no universitarias en Cataluña ${ }^{5}$, en el curso escolar 2015-2016, y el Registro Continuo de Población ${ }^{6}$. Se cuenta, por un lado, de información relativa al alumnado (año de nacimiento, sexo, curso escolar, etapa educativa, repetición de curso, superación del Grado de Educación Secundaria Obligatoria, existencia de necesidades educativas especiales) y de la escuela donde asiste (titularidad y localización), cruzada con las variables extraídas del Registro de Población, que hacen referencia tanto al propio alumno (lugar de residencia, año de primera y última entra-

4. En función del año de observación o de la fuente utilizada, los umbrales de concentración a partir de los cuales se observan efectos negativos sobre el rendimiento escolar varían. Estos umbrales varían desde un mínimo del $20 \%$ a valores que superan el $40 \%$.

5. La información sobre los escolares fue cedida desde el Departament d'Ensenyament de la Generalitat de Catalunya 6. El Registro Continuo de Población es la operación estadística resultado de relacionar el Padrón continuo de población con otros registros. 
da en Cataluña, nacionalidad y lugar de nacimiento) como a sus progenitores (residencia con los progenitores, lugar de origen y nacionalidad de los mismos).

Se ha analizado la información de 1.007.473 estudiantes, que son los que en Cataluña cursan la educación obligatoria (primaria y secundaria) más el segundo ciclo de educación infantil, cuya asistencia es generalizada. Siguiendo los trabajos de Rumbaut (2004), el alumnado ha sido clasificado mediante una tipología generacional que contempla el lugar de nacimiento propio y el de sus progenitores ${ }^{7}$, pero también el año de entrada a Cataluña. En este sentido, se ha diferenciado entre aquellos alumnos llegados con la educación obligatoria en curso de aquellos que entran con edades inferiores. A pesar de las críticas que algunas veces se efectúan sobre este tipo de clasificaciones, ya que perpetuán la identificación como "inmigrados" de menores nacidos en el país (y con la nacionalidad del país de recepción), hecho que puede contribuir a su estigmatización, la utilización de esta clasificación permite observar las desventajas que puede suponer el propio fenómeno migratorio con independencia de la nacionalidad del alumnado, así como desigualdades que bajo otras perspectivas se mantienen ocultas.

El resultado son las siguientes categorías, a las que nos referimos como estatus migratorio: 1) alumnado de primera generación: son nacidos en el extranjero e incorporados al sistema educativo catalán con siete o más años de edad; 2) alumnado de la generación 1,75: también nacidos en el extranjero, pero a diferencia de los anteriores se incorporan al sistema desde el inicio de la educación obligatoria, y por lo tanto llegan con menos de siete años de edad; 3) alumnado de segunda generación: son nacidos en España, aunque ambos progenitores han nacido en el extranjero; 4) alumnado de la generación 2,5: también nacidos en España, con uno de los progenitores nacido en el extranjero y el otro en España; y 5) alumnado autóctono: tanto el menor como sus progenitores (o el progenitor, en el caso de disponer únicamente de la información de uno de ellos) son nacidos en España. A pesar de la exhaustividad de la clasificación, para algunos casos no se dispone de toda la información estadística. Así se han recuperado los estudiantes nacidos en el extranjero y de los que se desconoce el año de llegada a Cataluña en la categoría de otros inmigrantes. Debe tenerse en cuenta en el análisis que en esta clasificación no interviene la nacionalidad de los menores ni la de sus progenitores. Así, puede producirse la situación de que un alumno clasificado como autóctono tenga nacionalidad extranjera, si tanto él como sus progenitores hubieran nacido en España y hubieran mantenido otra nacionalidad.

En segundo lugar, los resultados escolares se analizarán a partir de varios indicadores. Por un lado, las llamadas tasas de idoneidad, que calculan la proporción de alumnado de un origen determinado que se encuentra cursando el curso que le corresponde según su edad, en lo que sería la inversa de una tasa de repetición. Esta simple proporción se computa en dos momentos, para los últimos cursos de primaria (sexto de primaria) y secundaria (cuarto de la ESO). Para el curso escolar 2015-2016 esta aproximación se ha calculado empleando el año de nacimiento en 2004 y en 2000, respectivamente. Con los datos disponibles estas tasas se pueden calcular para todo el alumnado, con independencia de que se encuentren en el sistema público o el privado.

\footnotetext{
7. La taxonomía generacional no es unánimemente aceptada o utilizada, así se encuentran autores que hablan de la generación 1,75 (menores de 5 años) o de la generación 1,25 (entre 13 y 17 años) para referirse a la edad de llegada cuando hablan de menores, dato significativo en los estudios sobre escolaridad (Rumbaut, 2004). Por otro lado, la clasificación 1,5 se ha empleado frecuentemente para designar los descendientes de inmigrantes que como mínimo tienen un progenitor nacido en el país receptor, mientras otros más minoritarios, como el Servicio de Estadística Canadiense, utilizan la nomenclatura 2,5, ya que consideran que si se acepta que la 2 es la de la descendencia nacida en el país receptor de los inmigrados, y la 3 virtualmente fuera la de los autóctonos, aquellos que tuvieran un progenitor autóctono estarían más cerca de los autóctonos y por tanto les correspondería el 2,5 y no el 1,5 (utilizado generalmente cuando no se discrimina por la edad de llegada de los menores).
} 
Por otro lado, se analiza lo que muchas veces se considera como "fracaso escolar", que se corresponde a la no obtención del título de graduado de la ESO (Educación Secundaria Obligatoria). Con ello conocemos si se han adquirido las competencias básicas de la educación obligatoria. La no obtención de las mismas puede relacionarse con futuros problemas de integración laboral, de aquí su importancia de análisis. Estos datos sólo se disponen para los alumnos de las escuelas públicas catalanas, las cuales concentran alrededor del 75\% del alumnado relacionado con el proceso migratorio ${ }^{8}$. El cálculo del fracaso escolar se ha realizado en relación a los alumnos matriculados en el último curso de la ESO, operación que puede minimizar la incidencia del fracaso escolar ya que no recoge a los alumnos que no han alcanzado dicho curso y han abandonado el sistema con anterioridad al superar (o no) la edad de escolarización obligatoria.

Además del análisis realizado para el conjunto de alumnos de origen latinoamericano, se han seleccionado cinco casos que responden a situaciones diferenciadas, para su estudio en mayor profundidad: Bolivia, Ecuador, Argentina, Honduras y República Dominicana. Para su selección se considera a todos aquellos escolares que de forma directa o indirecta (a través del lugar de nacimiento de sus progenitores) tienen relación con estos orígenes, recuperando incluso la nacionalidad en aras de una mayor exhaustividad. En el hipotético caso de un menor de segunda generación que tenga progenitores que pertenezcan a orígenes distintos, el alumno se ha contabilizado en cada una de las categorías de forma independiente.

\section{Perfil de la población latinoamericana en Cataluña}

Los flujos migratorios desde Latinoamérica hacia Cataluña alcanzaron sus máximas intensidades a inicios de siglo XXI, cuando entre los años 2000 y 2008 llegan a producir la multiplicación de los efectivos residentes en Cataluña desde los 69 mil a los 491 mil empadronados. Con la crisis económica el crecimiento de los stocks se reduce, aunque alcanzan un máximo en 2012, con 527 mil migrados presentes. Desde entonces se registra un suave descenso en el número de inmigrados latinoamericanos ${ }^{9}$, situándose en 500.242 en 2015, y volviendo a aumentar en 2016 a $506.334^{10}$, año al que hace referencia nuestro trabajo, y que se sitúa en un momento de recuperación de las entradas producto de una mayor estabilidad económica, pero sobre todo por el mantenimiento de los factores de expulsión en los países de origen.

De esta forma, y a pesar de las consecuencias de la crisis económica, algunos orígenes de inmigrantes, entre ellos algunos países centroamericanos como Honduras más Venezuela, han seguido incrementado sus flujos durante estos últimos años, y con ello produciéndose la llegada de nuevos alumnos. A inicios de 2018 sigue observándose este crecimiento, alcanzando los 588.941 empadronados.

El perfil por sexo y edad de los inmigrantes latinoamericanos en Cataluña se caracteriza por una mayor presencia de mujeres (el 56,9\%), que se visibiliza en las edades alrededor de los 35 años

\footnotetext{
8. Para el curso 2015-2016 el Departament d’Ensenyament no disponía de estos datos para las escuelas privadas o concertadas. El Institut d'Infància i Adolescència de Barcelona (2019), para el caso de la ciudad de Barcelona en el curso 2016-2017, da una cifra de fracaso escolar del 5,7\% en los institutos privados, en comparación con el 15,6\% de los institutos públicos.

9. Para simplificar la recogida de datos, por latinoamericanos se considera a los nacidos en América menos los nacidos en Estados Unidos y Canadá. La presencia de inmigrados de otros países americanos no latinos es insignificante en Cataluña.

10. Como ejemplo de la disparidad de volúmenes si se considera el origen o la nacionalidad, en la misma fecha, el número de latinoamericanos contabilizados desde la perspectiva de la nacionalidad era de 240.068, menos de la mitad. Para simplificar la recogida de datos, por latinoamericanos se considera a los nacidos en América menos los nacidos en Estados Unidos y Canadá. La presencia de inmigrados de otros países americanos no latinos es insignificante en Cataluña.
} 
de edad (ver figura 1). Su mayor representatividad se relaciona con su intensa participación en el mercado laboral, en correspondencia a una elevada demanda por el trabajo doméstico y de cuidadoras en las sociedades de destino (Ribas-Mateos, 2004), en una situación de complementariedad socio-demográfica (Domingo, 2005) y de dualización del trabajo reproductivo (Fraser, 2017), en lo que representa un ejemplo paradigmático en la relación entre inmigración, roles de género y el lugar de la mujer en el mercado laboral (Giorguli y Angoa, 2016). Por otro lado, justo la mitad de la población latinoamericana ha adquirido la nacionalidad española, y con una edad media de 38,3 años. Es, además, una estructura etaria muy joven, con únicamente un 4,6\% de la población por encima de los 65 años de edad, y un peso reducido de los menores inmigrantes, un $8,5 \%$ se encuentra por debajo de los 18 años de edad.

Los cinco orígenes seleccionados en este trabajo muestran unos perfiles por sexo y edad que difieren en algunos aspectos del agregado general. Así, la pirámide de edades hondureña, con 26.153 personas, muestra una elevadísima feminización (un 72,7\%), producto de la novedad de unos flujos migratorios que normalmente encabezan las mujeres. Por el mismo motivo es un origen donde el acceso a la nacionalidad es menor, del 14,3\%, donde además se añade la coincidencia de una llegada reciente con medidas más restrictivas a la regularización de su situación administrativa debido a la etapa de crisis económica en la que arriban a España. Los menores de edad mantienen un peso importante, un 13,5\%, lo que significa una reagrupación de menores (o migraciones de arrastre) reciente.

Por su parte, el volumen de dominicanos es mayor, con 37.777 inmigrados. La feminización en este caso no es tan intensa $(59,8 \%)$, aunque también se concentra en las edades activas. La mayor antigüedad de esta migración provoca un mayor acceso a la nacionalidad, en un $54 \%$, con diferencias remarcables entre hombres $(48,9 \%)$ y mujeres $(57,9 \%)$, que han accedido con mayor intensidad a la nacionalización, en parte por su papel pionero en los flujos. En su estructura por edades, presentan un perfil también joven, con una edad media de 36 años. El caso de la población argentina, en cambio, es atípico dentro de la inmigración latinoamericana, ya que entre los 59.453 empadronados los hombres tienen una ligera mayor representación $(50,8 \%)$, con un perfil por edades que muestra un volumen de efectivos muy marcado entre los 30 y 40 años de edad, con sólo un 6,6\% de menores de edad. Si bien entre ellos la nacionalidad española se encuentra extendida (48,7\%), un buen número de ellos residen en Cataluña con la nacionalidad italiana $(19,7 \%)$, debido a la facilidad de acceso a la nacionalidad por parte de descendientes de este origen en Argentina, y a la entrada como ciudadanos comunitarios en su migración hacia España. La siguiente pirámide, la de los bolivianos, muestra de nuevo un perfil muy feminizado (el 60,4\% son mujeres), con presencia de adolescentes importante (un 11,4\% de menores de edad), donde se mantiene la nacionalidad extranjera en el $65 \%$ de los casos, mostrando un perfil que se caracterizó por su entrada en España en los momentos iniciales de la crisis económica. Finalmente, entre los 82.713 inmigrados del Ecuador la proporción de mujeres es menor $(54,5 \%)$ mientras que el porcentaje de los que tienen nacionalidad española es elevado $(67,6 \%)$, con prácticamente ningún menor de 15 años de edad nacido en origen. Esta es una característica compartida con la mayoría de orígenes, a excepción de los hondureños, y se debe a que en los flujos más antiguos la mayoría de menores ya han nacido en España. Estos menores, además, han obtenido automáticamente la nacionalidad española, para impedir que se quedaran como apátridas en aquellos países cuya legislación no contemplaba la transmisión de la nacionalidad a los nacidos fuera del país, como sucedía con Ecuador o Bolivia (Álvarez Rodríguez, 2006), y que pese a modificar sus constituciones con posterioridad, sus oriundos siguieron beneficiándose de esa práctica por defecto (Álvarez Rodríguez, 2014). 
Figura 1. Perfil por sexo y edad de la población según lugar de origen, Cataluña, 2016 Latinoamérica Honduras
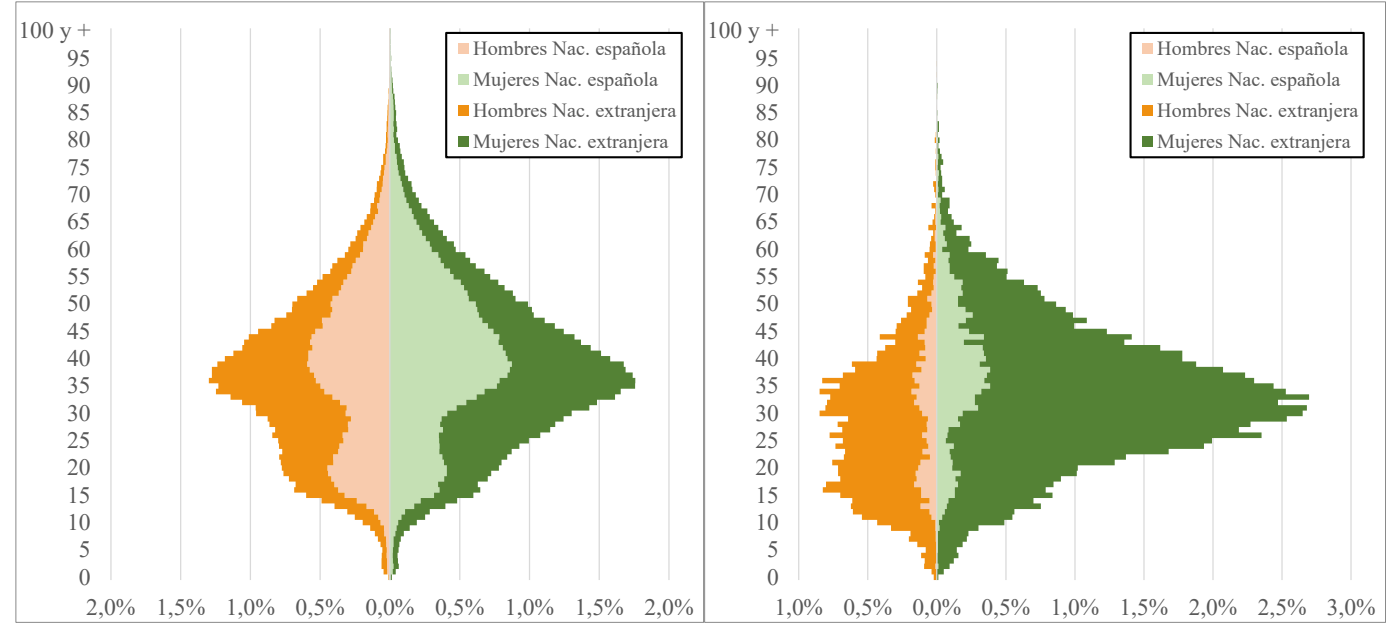

Rep. Dominicana

Argentina
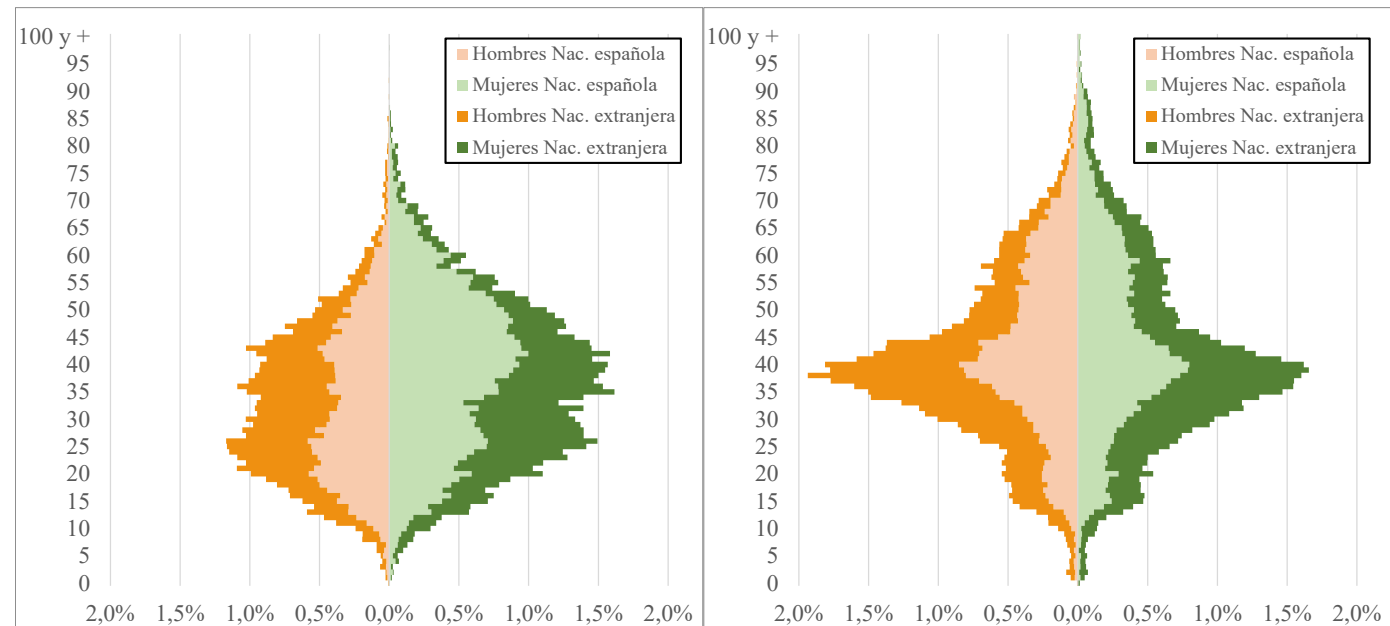

Bolivia

Ecuador

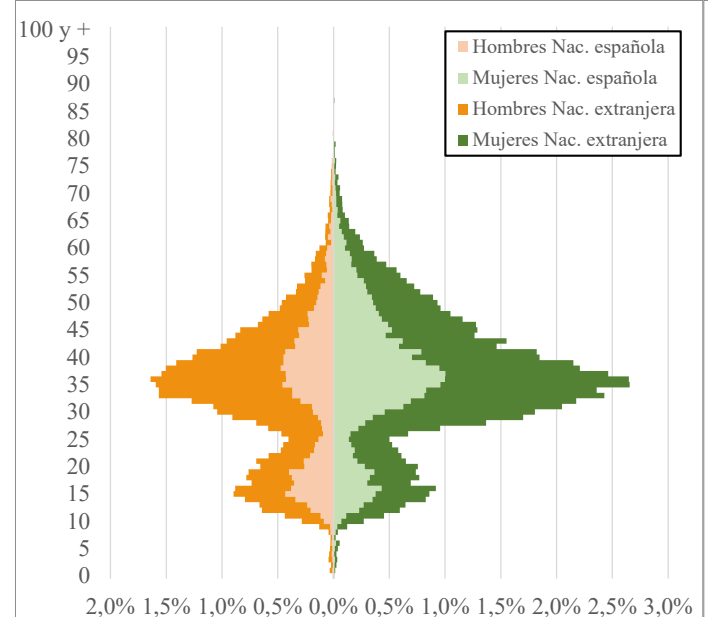

$100 \mathrm{y}+$
95
90
85
80
75
70
65
60
55
50
45
40
35
30
25
20
15
10
5
0

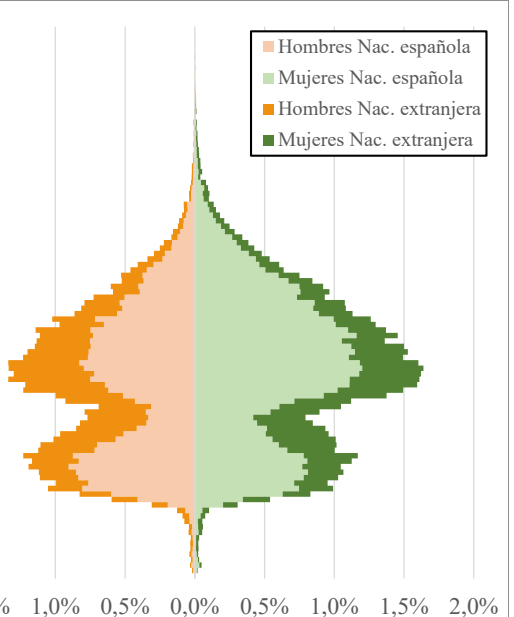

Fuente: Microdatos del INE del Padrón continuo de población, a 1 de enero de 2016. 


\section{El alumnado extranjero en Cataluña, 2002-2017}

El número de estudiantes extranjeros en la escuela en Cataluña conoció un intenso crecimiento en los primeros cursos del siglo (tabla 1), para posteriormente estabilizarse a partir del curso 2008-2009. Desde entonces las variaciones fueron de poca importancia, con ligeros aumentos hasta el curso 2011-2012 y un pequeño descenso posterior. En relación al total de alumnos, los alumnos extranjeros duplican su representatividad en sólo tres cursos: del 5,3\% del curso 20022003 al 10,2\% del 2005-2006, coincidiendo con los años de crecimiento más intensos del fenómeno migratorio en Cataluña. El máximo se alcanza en el curso 2008-2009, con el 13,2\% de los alumnos, porcentaje que se mantiene o incluso desciende desde entonces hasta el 12,2\% de alumnos extranjeros en el curso 2016-2017.

Tabla 1. Evolución del alumnado extranjero en Cataluña, por curso escolar y etapa educativa

\begin{tabular}{|l|r|r|r|r|r|r|r|r|}
\hline & $\begin{array}{r}\text { Ed. infantil } \\
(1 \text { ciclo })\end{array}$ & $\begin{array}{r}\text { Ed. infantil } \\
(2 \text { ciclo })\end{array}$ & $\begin{array}{r}\text { Ed. } \\
\text { primaria }\end{array}$ & $\begin{array}{r}\text { Ed. } \\
\text { especial }\end{array}$ & ESO & Bachillerato & $\begin{array}{r}\text { Otros } \\
\text { secundaria }\end{array}$ & TOTAL \\
\hline $2002-2003$ & - & 11.841 & 22.636 & 383 & 14.955 & 2.286 & 1.908 & 54.006 \\
\hline $2003-2004$ & 2.418 & 15.275 & 32.761 & 536 & 20.233 & 3.040 & 2.704 & 76.995 \\
\hline $2004-2005$ & 2.860 & 17.318 & 40.245 & 699 & 23.532 & 3.665 & 3.622 & 91.941 \\
\hline $2005-2006$ & 3.508 & 18.789 & 47.020 & 749 & 31.160 & 4.292 & 4.648 & 110.166 \\
\hline $2006-2007$ & 4.091 & 20.036 & 53.901 & 864 & 35.864 & 5.049 & 5.909 & 125.714 \\
\hline $2007-2008$ & 4.443 & 22.062 & 59.992 & 1.027 & 42.444 & 5.707 & 7.152 & 142.827 \\
\hline $2008-2009$ & 5.055 & 23.487 & 63.159 & 1.197 & 47.528 & 6.222 & 10.298 & 156.945 \\
\hline $2009-2010$ & 5.220 & 23.214 & 60.489 & 1.147 & 48.454 & 6.930 & 12.425 & 157.879 \\
\hline $2010-2011$ & 3.985 & 27.241 & 60.446 & 1.206 & 49.149 & 7.563 & 14.437 & 164.027 \\
\hline $2011-2012$ & 4.130 & 31.670 & 58.579 & 1.365 & 48.253 & 8.172 & 16.406 & 168.575 \\
\hline $2012-2013$ & 3.544 & 35.519 & 56.598 & 1.411 & 45.713 & 8.478 & 17.219 & 168.486 \\
\hline $2013-2014$ & 3.246 & 38.291 & 55.009 & 1.356 & 42.064 & 8.301 & 16.595 & 164.862 \\
\hline $2014-2015$ & 3.526 & 37.938 & 55.928 & 1.418 & 38.724 & 7.939 & 16.587 & 162.060 \\
\hline $2015-2016$ & 3.878 & 37.321 & 58.332 & 1.382 & 36.147 & 8.007 & 16.587 & 161.654 \\
\hline $2016-2017$ & 4.089 & 35.160 & 60.759 & 983 & 34.922 & 7.541 & 16.055 & 159.509 \\
\hline
\end{tabular}

Fuente: Elaboración propia con datos del web del Departament d'Ensenyament

Esta dinámica difiere según etapa escolar, mientras en los dos ciclos educativos de infantil la cifra de alumnos extranjeros se mantiene elevada, o incluso vuelve a crecer en primaria, en la Educación Secundaria Obligatoria (ESO) se registra un descenso importante en los últimos cursos. Además de las nuevas entradas, la evolución del volumen del alumnado extranjero viene mediatizada por lo que sucede en relación a los procesos de nacionalización, con estudiantes que desaparecen de observación a medida que aumentan sus años de escolarización debido a la adquisición de la nacionalidad española.

Actualmente el mayor número de alumnos extranjeros se encuentra en la educación primaria (más de 60 mil), y en menor medida en secundaria y el segundo ciclo de educación infantil. En primaria llegaron a representar el 15\% del alumnado, aunque su peso ha descendido al $12,6 \%$ del curso 2016-2017, descenso que coincide con la entrada en secundaria de las generaciones nacidas en los años del repunte de la fecundidad, a inicios de siglo XXI, justo antes de la crisis económica. En la ESO la dinámica es distinta, con un descenso sostenido de los efectivos desde el curso 20102011, y de 49.149 matriculados y el 17,8\% de la matrícula total a un 11,5\% y 34.922 alumnos. 


\section{El alumnado de origen latinoamericano: perfiles migratorios y por origen}

Considerando la suma de los estudiantes nacidos en Latinoamérica más los descendientes de inmigrados latinoamericanos, en lo que a partir de ahora consideramos como alumnos de origen latinoamericano, encontramos que el número de matriculados en enseñanzas no universitarias en Cataluña durante el curso 2015-2016 asciende a 117.476 escolares, siendo el primer gran origen entre los inmigrados y sus descendientes en Cataluña, por encima de los 81.578 estudiantes identificados como originarios del Magreb, o de los 61.600 de la Europa comunitaria. Esta cifra supera ampliamente a la obtenida desde otras perspectivas de análisis, como las que habitualmente consideran el alumnado bajo el prisma de la nacionalidad. En este caso, y estudiando el alumnado extranjero, la cifra barajada es la de 30.431 alumnos con nacionalidad de un país latinoamericano. De forma menos habitual, en cambio, se emplea la perspectiva del país de nacimiento, considerando al alumnado inmigrado. En este último caso se considera a los 49.938 nacidos allí. Si en este recuento se considera solo a los estudios obligatorios (más el segundo ciclo de infantil), los datos nos indican cómo este volumen se reduce a los 93.920 estudiantes, o lo que es lo mismo, hasta el 9,3\% del total de escolares, que son los que se analizaran a continuación. Desde la perspectiva de la nacionalidad (22.912 alumnos) o el lugar de nacimiento (29.213) las cifras son menores, dando lugar a diferentes fotografías y análisis sobre una misma realidad.

En una elevada proporción, estos alumnos identificados como latinoamericanos tienen la nacionalidad española (71,6\%), ya sea por nacionalización o por nacimiento. También en un notable porcentaje ya han nacido en España (el 67,7\% de los casos). Entre estos últimos, los nacidos en España, únicamente el $13 \%$ se registra con una nacionalidad extranjera, porcentaje muy inferior al de otros orígenes (un 50,4\% de los marroquíes o un 61,6\% de los pakistaníes, por ejemplo), mientras que un $39,3 \%$ de los nacidos fuera han adquirido la nacionalidad.

Tabla 2. Alumnos de origen latinoamericano en Cataluña, curso 2015-2016, según el estatus migratorio y la nacionalidad ${ }^{11}$

\begin{tabular}{|c|c|c|c|c|c|c|}
\hline & $\begin{array}{r}\text { Nacionalidad } \\
\text { española }\end{array}$ & $(\%)$ & $\begin{array}{r}\text { Nacionalidad } \\
\text { extranjera }\end{array}$ & $(\%)$ & Total & ( $\%$ columna) \\
\hline Primera Generación & 3.521 & 29,2 & 8.528 & 70,8 & 12.049 & 12,8 \\
\hline Generación 1,75 & 7.763 & 49,0 & 8.075 & 51,0 & 15.838 & 16,9 \\
\hline Segunda Generación & 31.992 & 81,6 & 7.213 & 18,4 & 39.205 & 41,7 \\
\hline Generación 2,5 & 23.296 & 99,7 & 63 & 0,3 & 23.359 & 24,9 \\
\hline Autóctonos & 4 & 7,5 & 49 & 92,5 & 53 & 0,1 \\
\hline Otros inmigrados & 640 & 26,1 & 1.813 & 73,9 & 2.453 & 2,6 \\
\hline Otros & 20 & 2,1 & 943 & 97,9 & 963 & 1,0 \\
\hline Total & 67.236 & 71,6 & 26.684 & 28,4 & 93.920 & 100,0 \\
\hline
\end{tabular}

Fuente: Elaboración propia con datos del Departament d’Ensenyament e Idescat.

Fruto del arraigo migratorio y de unos flujos migratorios ya consolidados en el tiempo, entre los escolares de origen latinoamericano la situación más representada en relación a la tipología migratoria es la de las segundas generaciones, con más de 39 mil alumnos en Cataluña. Hasta ahora, estos alumnos son mayoritariamente invisibilizados estadísticamente, ya que son nacidos

11. Se consideran a los alumnos que cursan el segundo ciclo de infantil, la educación primaria y la secundaria obligatoria 
en España y poseen la nacionalidad española (en un 81,6\%, ver cuadro 2). En la generación 2,5 encontramos 23 mil alumnos más, una cuarta parte del alumnado, lo que indica una elevada presencia de matrimonios mixtos en comparación a otros orígenes, y la progresiva incorporación de sus descendientes a la escuela. El tercer grupo en importancia es el de la Generación 1,75 donde se encuentran aquellos inmigrados llegados a edades tempranas, con anterioridad a su incorporación en la escuela primaria. Su mayor representación relativa en comparación a los alumnos de primera generación es producto de los últimos años de crisis económica, donde se ralentizó la entrada de inmigrantes, especialmente latinoamericanos, e inclusive creció el retorno. En ambos casos estos alumnos ostentan nacionalidades extranjeras, en un 70,8\% entre la primera generación y en un $51 \%$ en la generación 1,75 .

\subsection{El análisis de algunos orígenes específicos}

Los cinco orígenes considerados en este trabajo muestran diferencias relevantes en la composición del alumnado (ver tabla 3). En el caso de Ecuador, este es el segundo origen en Cataluña con 17.505 matriculados (en un 48,5\% niñas), a mucha distancia de los 70.414 marroquíes. Se trata de un colectivo con una presencia prolongada en Cataluña, y donde el 81,5\% de los estudiantes tienen nacionalidad española. En tres de cada cuatro casos han nacido en España, situaciones que se corresponden con segundas generaciones. En su distribución por cursos esta circunstancia es mayoritaria, a excepción de los dos últimos de la ESO, donde dominan aquellos nacidos en el país de origen. En realidad, esto denota como a inicios de siglo XXI en España la presencia de ecuatorianos era aún muy incipiente, sin apenas nacimientos en el país (ver figura 2). En el caso del alumnado argentino, los 11.717 estudiantes se configuran como uno de los orígenes más importantes en la escuela (en un $48,6 \%$ de sexo femenino). Mayoritariamente ostentan la nacionalidad española (el 74\%), o bien otra nacionalidad diferente a la argentina (el 14,5\%, en buena parte italianos). En comparación a otros orígenes destaca el peso de la Generación 2,5 ya que alcanza el 36,9\%. Para los bolivianos contamos con 9.587 alumnos, con equilibrio entre sexos y de llegada más reciente, como evidencia el peso de la primera generación (el 17,7\%), y con un $44 \%$ de los efectivos nacidos fuera de España. En la ESO, pero también en los últimos cursos de primaria, dominan los alumnos nacidos en el extranjero. Por su parte los alumnos de origen dominicano suman 8.584 casos, en un $70 \%$ con nacionalidad española y también con un equilibrio entre chicos y chicas. En este caso la representación de las segundas generaciones es muy importante aunque, a diferencia de otros orígenes, siguen siendo relativamente importantes las primeras generaciones (el 18,5\%).

Un perfil diferente de los anteriores es el del alumnado hondureño, ya que se trata de uno de los últimos grupos nacionales que emigran hacia España, siendo además el único caso donde se observa un mayor número de chicos (el 50,7\%). Con 4.999 casos, observamos un bajo peso de las nacionalizaciones, ya que sólo el $23,5 \%$ de estos tiene nacionalidad española, y hasta un $35,9 \%$ de los mismos pertenecen a la primera generación. A pesar de ello, ya en la educación infantil y en los primeros cursos de primaria se observa un mayor peso de los descendientes de inmigrados. 
Tabla 3. Alumnado de origen latinoamericano en Cataluña, curso 2015-2016, según el estatus migratorio y la nacionalidad ${ }^{12}$

\begin{tabular}{|l|r|r|r|r|r|r|r|r|r|r|}
\hline & \multicolumn{2}{|c|}{ Argentina } & \multicolumn{2}{|c|}{ Bolivia } & \multicolumn{2}{c|}{ Ecuador } & \multicolumn{2}{c|}{ Honduras } & \multicolumn{2}{c|}{$\begin{array}{c}\text { Rep. } \\
\text { Dominicana }\end{array}$} \\
\hline & abs. & $(\%)$ & abs. & $(\%)$ & abs. & $(\%)$ & abs. & $(\%)$ & abs. & $(\%)$ \\
\hline Primera generación & 526 & 4,5 & 1.696 & 17,7 & 1.554 & 8,9 & 1.794 & 35,9 & 1.588 & 18,5 \\
\hline Generación 1,75 & 2.133 & 18,2 & 2.312 & 24,1 & 2.421 & 13,8 & 897 & 17,9 & 967 & 11,3 \\
\hline Segunda generación & 4.486 & 38,3 & 4.490 & 46,8 & 10.633 & 60,7 & 1.343 & 26,9 & 4.050 & 47,2 \\
\hline Generación 2,5 & 4.324 & 36,9 & 696 & 7,3 & 2.461 & 14,1 & 400 & 8,0 & 1.605 & 18,7 \\
\hline Otros inmigrados & 228 & 1,9 & 206 & 2,1 & 237 & 1,4 & 364 & 7,3 & 243 & 2,8 \\
\hline Otros casos & 20 & 0,2 & 187 & 2,0 & 199 & 1,1 & 201 & 4,0 & 131 & 1,5 \\
\hline Total & 11.717 & 100,0 & 9.587 & 100,0 & 17.505 & 100,0 & 4.999 & 100,0 & 8.584 & 100,0 \\
\hline
\end{tabular}

Fuente: Elaboración propia con datos del Departament d’Ensenyament e Idescat

En la figura 2 se ha representado para el conjunto de latinoamericanos y los cinco orígenes considerados el estatus migratorio junto con la nacionalidad en función de la etapa escolar y el curso. Si bien las cifras de alumnos son similares entre cursos, entre un máximo que supera los 8 mil escolares y un mínimo por encima de los seis mil, la composición de los mismos según el estatus migratorio varia de forma considerable entre cursos y etapas. De esta forma, en el último curso de ESO los pertenecientes a la primera generación son el grupo más importante, relacionado con la continua llegada de menores por inmigración pero también con el descenso de los flujos migratorios durante los últimos años a raíz de la crisis económica. Entre los cinco orígenes encontramos perfiles distintos. Por un lado, orígenes de llegada reciente, como el significativo caso hondureño, donde la primera generación es el principal estatus a partir de cuarto curso de primaria. Para Ecuador, Argentina y Bolivia la generación 1,75 es también muy importante en secundaria, reflejo de unos flujos migratorios de mayor entidad antes de la crisis económica. Otro aspecto a destacar, y a diferencia de otros orígenes (ver Bayona y Domingo, 2018b, para los marroquíes), la generación 2,5 tiene un notable peso entre los latinoamericanos. Si la atención se centra en la nacionalidad, en algunos orígenes, como el ecuatoriano o en menor medida los bolivianos, se produce una práctica desaparición de los mismos en la educación primaria, si se contemplan las barras verticales que indican la nacionalidad de los escolares.

Finalmente, y en relación al análisis de los resultados educativos, es necesario observar cual es la composición por orígenes del último curso de la ESO. Los alumnos latinoamericanos que cursan cuarto de ESO ascienden a 7.580, de los cuales 5.634 se encuentran en centros públicos, que serán los que se analizarán. La composición por estatus migratorio de estos escolares indica una fuerte importancia de la primera generación (45,6\%), pero también de la generación 1,75 (el 33,7\%). De esta forma, hasta un 83,5\% de los alumnos (si sumamos aquellos sin datos del año de llegada, clasificados como otros inmigrantes) han nacido fuera de España, en una situación que cambiará con total seguridad en un futuro próximo, ya que a pesar del más que posible nuevo incremento de los flujos por la mejora de las condiciones económicas, los alumnos nacidos en España adquirirán un peso mucho mayor. 
Figura 2. Alumnado según etapa y curso, estatus migratorio y nacionalidad, Cataluña, curso 2015-2016.
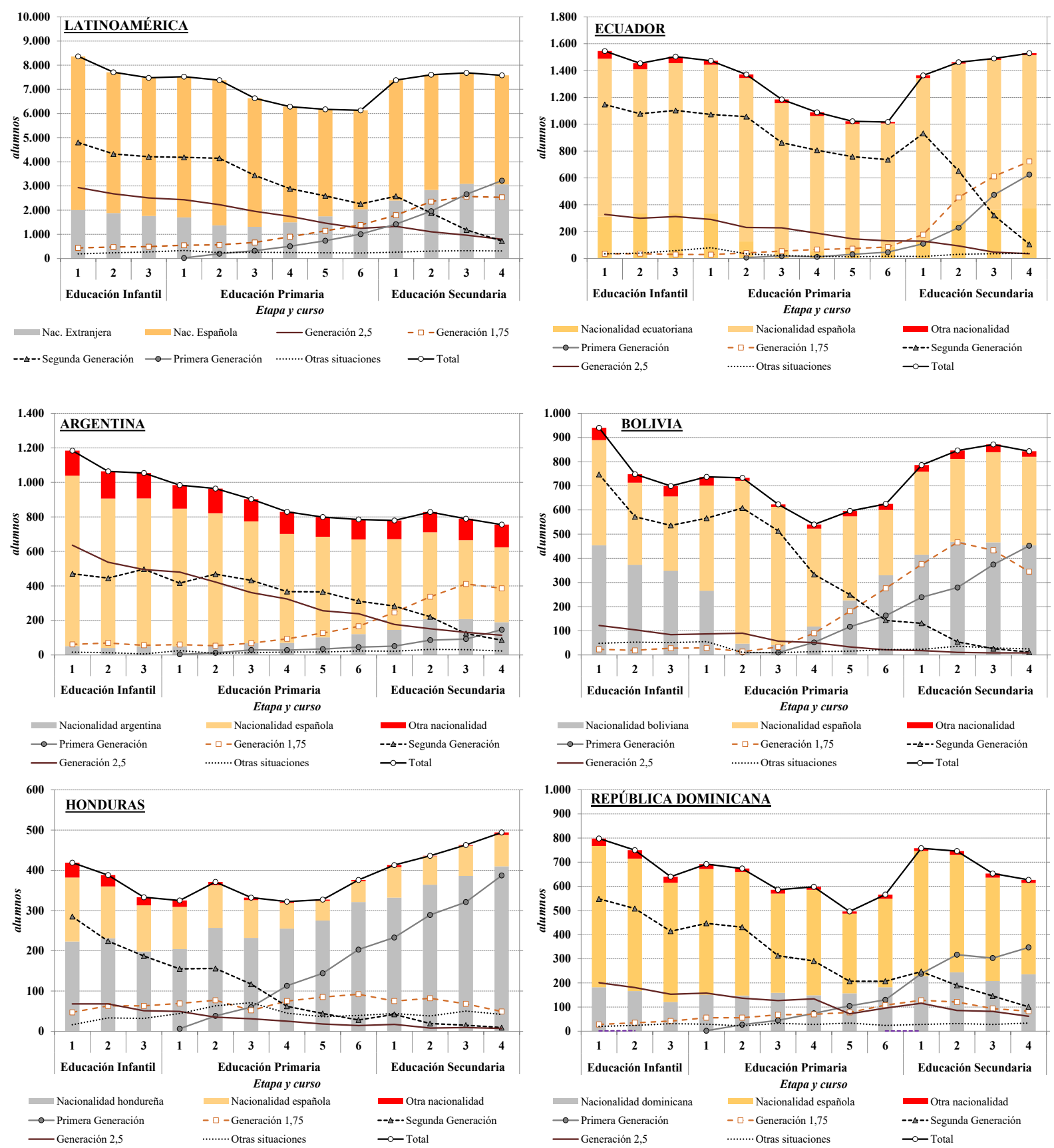

Fuente: Elaboración propia con datos del Departament d'Ensenyament e Idescat

\subsection{La discontinuidad en la escuela}

Una de las posibilidades que nos ofrece la base de datos creada es el análisis de la discontinuidad en la escuela, definida como aquella situación donde el año de primera y última llegada a Cataluña no son coincidentes. Aunque desconocemos el tiempo que pasan fuera de Cataluña y si se produce un retorno al país de origen o una reemigración hacia otro destino, tanto hacia el resto de España como a un tercer país, la discontinuidad dentro del sistema escolar puede afectar tanto 
al éxito en el rendimiento escolar como perpetuar las perturbaciones del proceso migratorio en menores nacidos en España.

Entre los latinoamericanos, alrededor de 14 mil matriculados, el 12,4\% de los alumnos con datos, habrían experimentado una discontinuidad, por apenas un 3\% de los autóctonos. Por etapa escolar, la prevalencia de estas situaciones superaría el 15\% de los alumnos en la ESO (tan sólo los originarios de países del sur de Asia mostrarían valores superiores), mientras que según el estatus migratorio serían las generaciones 1,75 las que experimentarían este proceso en mayor medida, en un $19,8 \%$ de los $\operatorname{casos}^{13}$. Un 11,9\% de las segundas generaciones también conocerían este proceso. La discontinuidad podría estar relacionada con los efectos de la crisis económica, con el retorno momentáneo de algunos menores en momentos de dificultad económica, pero también con estrategias de crianza de los hijos. Debido a estos factores la discontinuidad es muy distinta entre orígenes. Así, en un 15,7\% de los alumnos de segunda generación dominicanos encontraríamos esta situación, por sólo un $8,9 \%$ de los argentinos. Los valores más elevados se experimentan entre los escolares de la generación 1,75, con el 25,3\% de los bolivianos y el 26,6\% de los ecuatorianos.

\section{Inmigración y resultados escolares}

La idoneidad, entendida como la correspondencia entre la edad del alumno y el curso en que se encuentra, es un indicador que mide la dificultad en la progresión escolar, que se ha utilizado en otras ocasiones (ver, por ejemplo, el Pla per a la reducció del fracàs escolar a Catalunya 2012-2018, del Departament d'Ensenyament), y que resulta complementaria a los indicadores de éxito (o fracaso) escolar, aunque no representa lo mismo. No obstante, en nuestro caso, amplía la cobertura de los datos a todo el alumnado. Debemos tener presente que la decisión de repetir curso o de ingresar en un curso inferior es una decisión del equipo pedagógico, en el que intervienen factores directamente relacionados con el momento de llegada del menor, y que afecta especialmente a la primera generación, y en menor medida a la generación 1,75. En esta decisión intervienen el momento del calendario en el que se incorpora el alumno, la comprensión lingüística, y la adecuación de los sistemas escolares y las competencias contempladas en origen y en el sistema escolar catalán, además de las dificultades de aprendizaje que presente el propio alumno. Las tasas de idoneidad se representan en la figura 3, para los cinco orígenes considerados. Entre los ecuatorianos, la tasa de idoneidad a finales de primaria es muy similar a la global, tan sólo dos puntos por debajo (90,4\% por $92,4 \%$ ), con un $91,3 \%$ entre el grupo con mayores efectivos, la segunda generación, y sin apenas diferencias entre sexos. En secundaria la tasa se reduce al 58,4\%, muy inferior al 78,9\% global, por una composición generacional más diversa, donde la segunda generación es apenas representativa, y donde tiene un peso importante la primera generación, cuyos alumnos presentan valores incluso inferiores al $50 \%$.

Algunos de estos parámetros se repiten entre los argentinos, aunque en este caso la Generación 1,75 experimenta unos valores más elevados, e incluso cuando el menor es nacido en España los resultados son mejores que la media. En el resto de orígenes los perfiles son parecidos a los aquí mostrados. Destaca entre los bolivianos la baja tasa de idoneidad de los alumnos de primera generación, apenas un 40\%, valor muy similar a la de los dominicanos. En este último caso las tasas son también bajas entre las segundas generaciones, por debajo del 70\%, o en la Generación

13. En esta ocasión, la primera generación presenta porcentajes de discontinuidad menores, en parte porque muchos de ellos han llegado de forma reciente, sin tiempo material para efectuar este desplazamiento. 
2,5 donde se supera por poco el $80 \%$. Finalmente, entre los hondureños se repiten los mismos perfiles, aunque en esta ocasión los datos no son representativos en el caso de los descendientes.

Figura 3. Tasas de idoneidad según origen y estatus migratorio, 2015-16

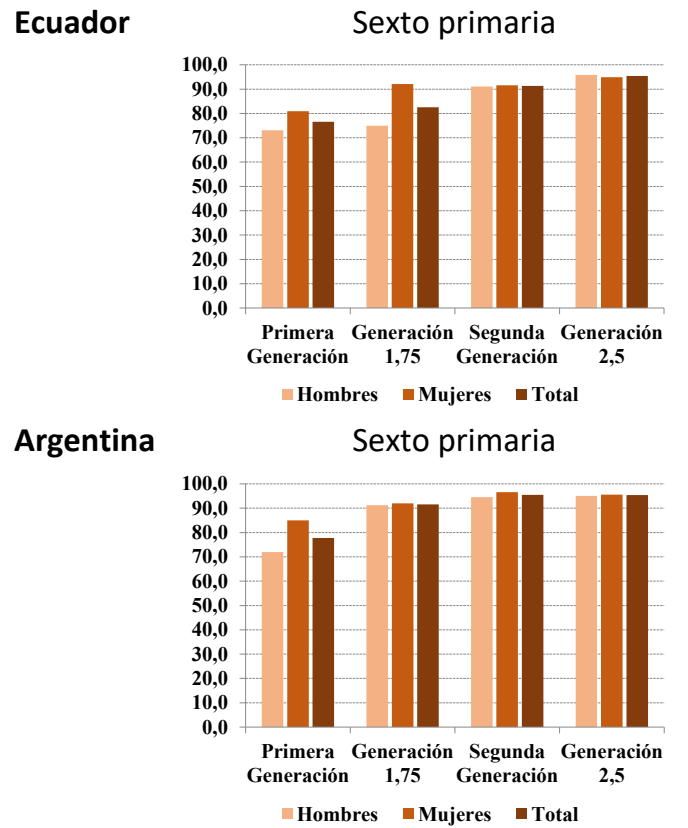

Bolivia
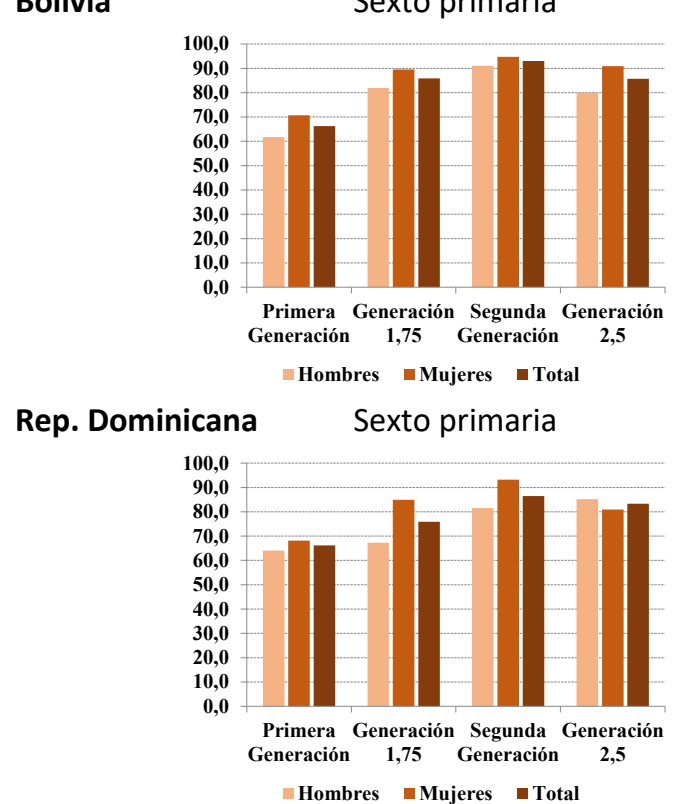

Honduras

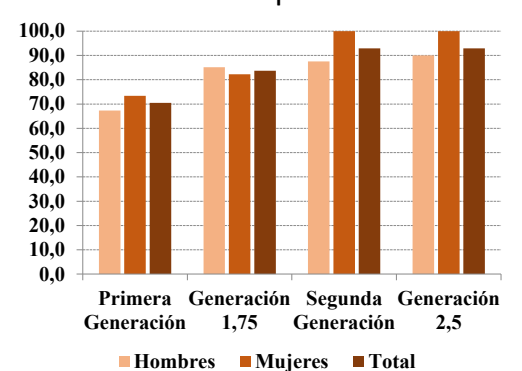

Cuarto de ESO

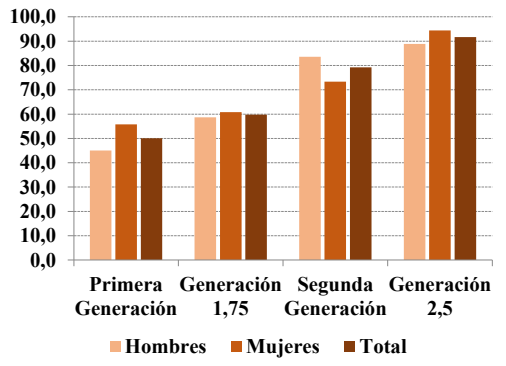

Cuarto de ESO

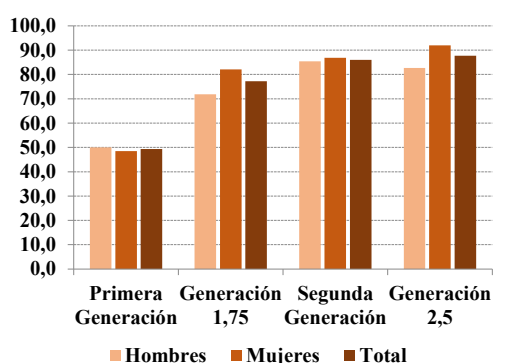

Cuarto de ESO

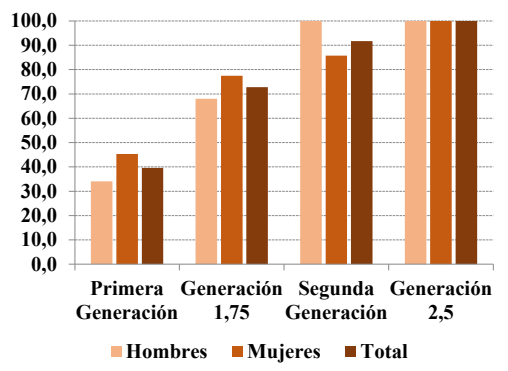

Cuarto de ESO

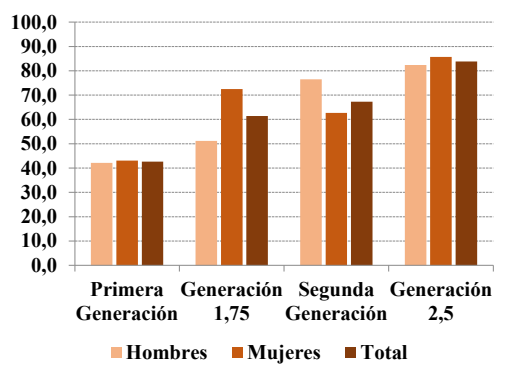

Cuarto de ESO

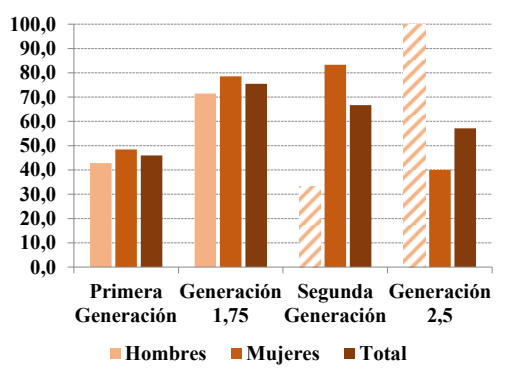

Fuente: Elaboración propia con datos del Departament d'Ensenyament e Idescat 
En segundo lugar, los resultados escolares son analizados a partir de la proporción de alumnos que no obtienen el título de la ESO. Aquí volvemos a observar cómo el proceso migratorio representa una fuerte perturbación sobre los resultados escolares. Si un 10,3\% de los alumnos autóctonos no obtienen el graduado de la $\mathrm{ESO}^{14}$, entre los alumnos de primera generación el porcentaje asciende al 29,2\%, con un fracaso escolar que triplica al de los autóctonos (ver tabla 4). Entre los llegados a muy corta edad, la generación 1,75 , este valor se sitúa en el 16,7\%, equiparándose con la segunda generación. Este resultado conlleva a una doble interpretación. Por un lado, la llegada temprana no representa un inconveniente mayor que haber nacido aquí, por el otro, los hijos de los inmigrados, aun habiendo nacido en España, siguen mostrando una preocupante distancia en relación a los autóctonos en los resultados escolares. En cambio, cuando analizamos la generación 2,5 no se observan diferencias en relación a los autóctonos.

Entre los alumnos latinoamericanos, los valores presentados no se alejan de los globales, a pesar de su mayor cercanía lingüística con la población autóctona. Sigue existiendo una relación directa entre migración y resultados obtenidos, con un elevado fracaso entre las primeras generaciones (el 32,7\%). Incluso la generación 1,75 muestra peores resultados que los globales, con un 18,2\%. Para este grupo de alumnos la discontinuidad sí que es un elemento importante en la posibilidad de alcanzar la titulación, con valores del 22,4\% y el 16,8\% en función de si se es discontinuo o no. Únicamente entre el alumnado de la segunda generación se mejoran los resultados del conjunto de descendientes de inmigrados. De hecho, entre las segundas generaciones los alumnos de origen asiático $(17,8 \%)$ y africano $(19,2 \%)$ obtienen tasas más elevadas, entre estos últimos con valores que superan el $30 \%$ para los subsaharianos.

Tabla 4. Proporción de alumnos que no obtienen el título de ESO en escuelas públicas, por origen y estatus migratorio, curso 2015-2016, Cataluña.

\begin{tabular}{|l|r|r|r|r|r|r|}
\hline & \multicolumn{3}{|c|}{ Total alumnos } & \multicolumn{3}{c|}{ Alumnos latinoamericanos } \\
\hline & Hombres & Mujeres & Total & Hombres & Mujeres & Total \\
\hline Autóctonos & 13,2 & 7,3 & 10,3 & & & \\
\hline Generación 2,5 & 12,5 & 7,7 & 10,1 & 12,5 & 10,0 & 11,2 \\
\hline Segunda Generación & 21,2 & 13,7 & 17,3 & 18,3 & 11,6 & 15,0 \\
\hline Generación 1,75 & 21,7 & 12,2 & 16,7 & 23,0 & 13,5 & 18,2 \\
\hline Primera Generación & 34,6 & 23,5 & 29,2 & 32,7 & 22,9 & 27,8 \\
\hline Total alumnos & 17,4 & 10,4 & 13,9 & 26,6 & 19,1 & 23,4 \\
\hline
\end{tabular}

Fuente: Elaboración propia con datos del Departament d’Ensenyament e Idescat

Desde la perspectiva de género, las mujeres presentan mejores resultados. Incluso la distancia entre sexos aumenta a medida que empeoran los resultados escolares. De esta forma, entre el total de alumnos de primera generación la brecha entre hombres y mujeres es de once puntos porcentuales, con un elevado fracaso del 34,6\% entre los hombres. Entre los alumnos latinoamericanos las diferencias se mantienen, aunque son ligeramente inferiores entre la primera generación (casi diez puntos).

14. La no obtención del título no significa que este no pueda obtenerse con posterioridad 
Figura 4. Porcentaje de alumnado que no obtiene el título de la ESO según origen, curso 2015-2016. ${ }^{15}$

\section{Latinoamericanos}

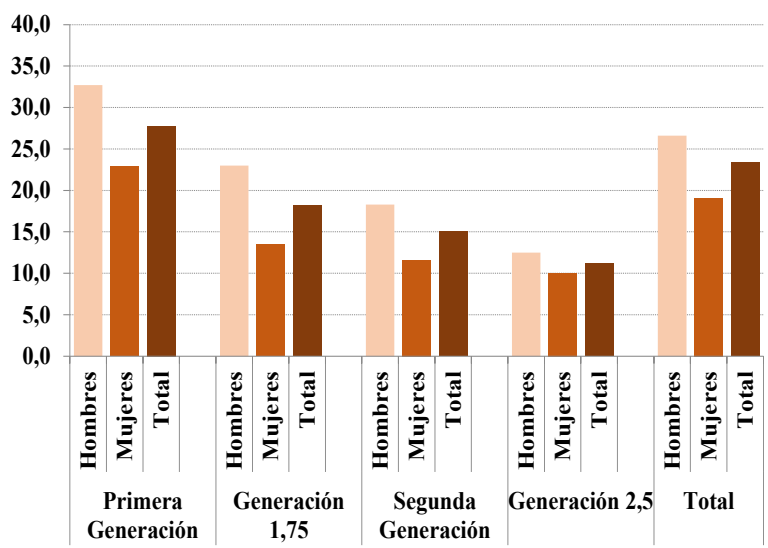

Argentina

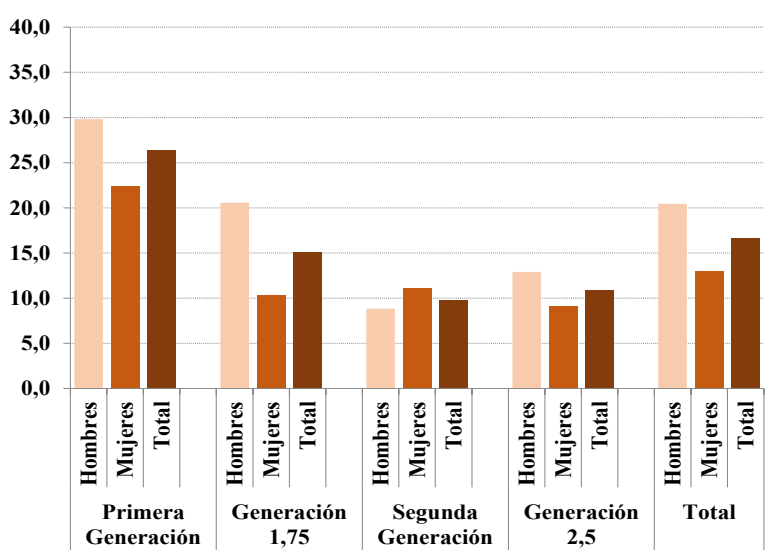

Rep. Dominicana

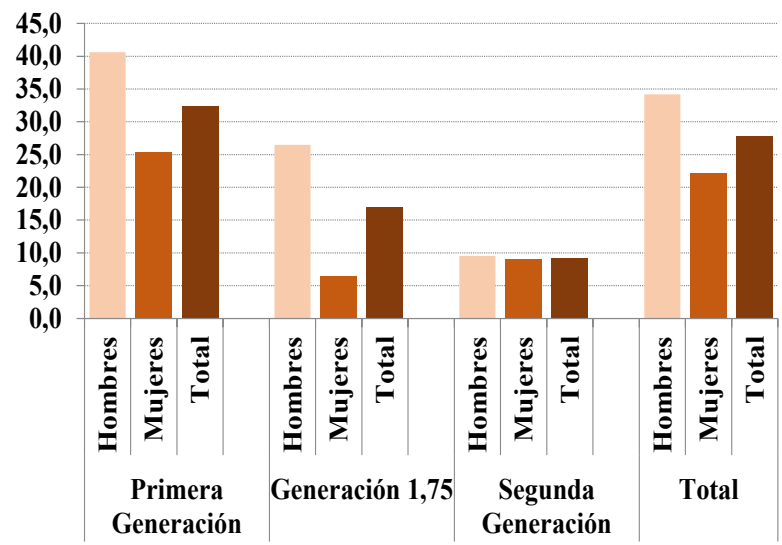

Ecuador

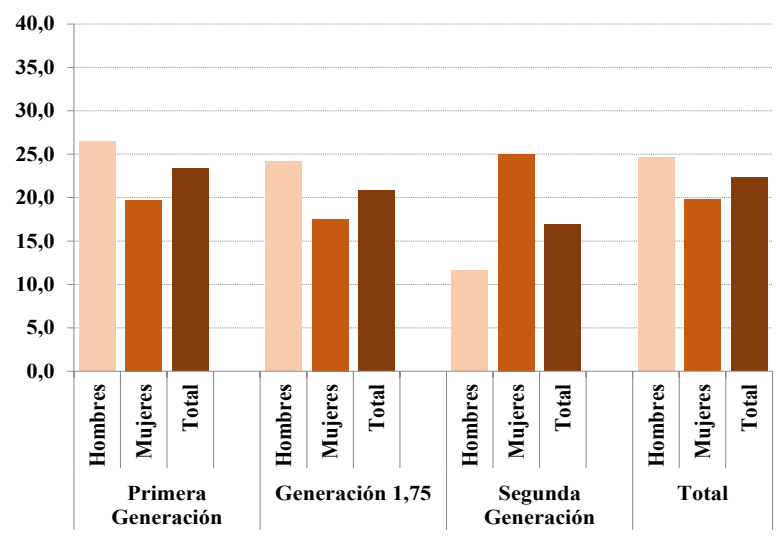

Bolivia

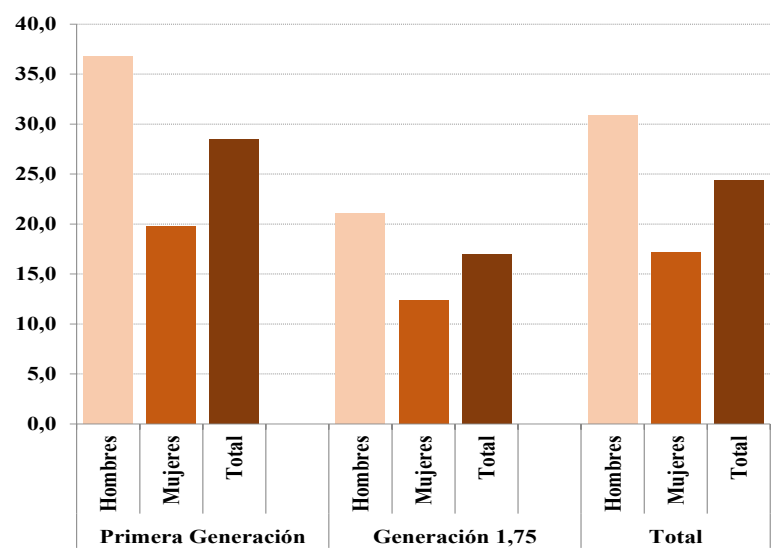

Honduras

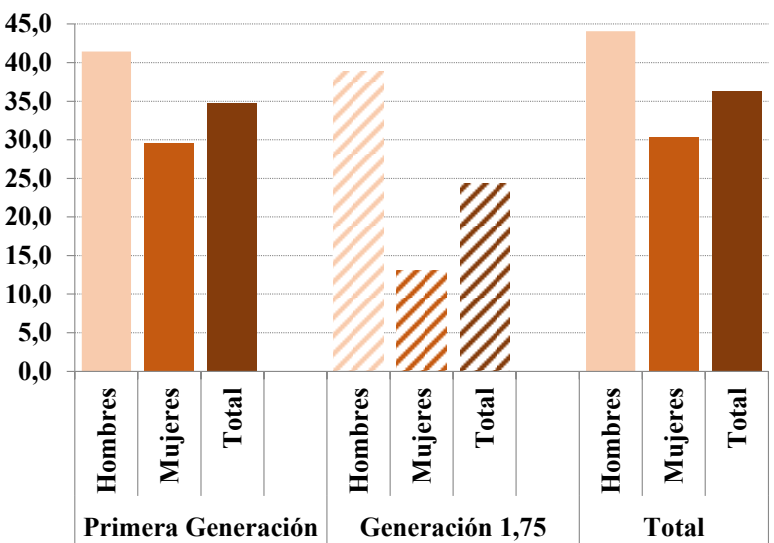

Fuente: Elaboración propia con datos del Departament d'Ensenyament e Idescat

15. Las barras con tramas discontinuas indican la existencia de un bajo número de alumnos, con lo que los resultados deben ser leídos con precaución. En los casos donde el volumen de alumnos es muy bajo, ya no se representan las barras. 
En la figura 4 estos resultados se han representado para los cinco orígenes presentados en este trabajo. Entre los ecuatorianos, contamos con 1.171 menores en el último curso de ESO en escuelas públicas, en su gran mayoría (92\%) nacidos en el extranjero. Un 22,3\% de ellos no obtienen la titulación, al mismo nivel que el grupo con mayores efectivos, los marroquíes (Bayona y Domingo, 2018b). Esta situación es mayor entre los hombres (24,7\% por 19,8\%), aunque las diferencias entre sexos se minimicen. Entre los dos subgrupos con mayor alumnado, los de primera generación obtienen peores resultados que la generación 1,75 , con una distancia corta $(23,3 \%$ por 20,8\%), donde se mantienen los mismos desequilibrios por sexo. Los resultados mejoran en la segunda generación (16,9\%), aun siguen lejanos al conjunto de alumnos. Para los alumnos de origen argentino los resultados son analizados para 575 alumnos, que en un $70 \%$ nacieron fuera de España, aunque llegaron generalmente a corta edad. La obtención de la titulación sigue siendo inferior a la media, con un $16,6 \%$ que no la alcanza, superando incluso valores del $20 \%$ entre los chicos. Las cifras más elevadas se observan entre la primera generación, cuando se sobrepasa entre los chicos el 30\%. En cambio, en la segunda generación y la generación 2,5 los resultados son incluso mejores que la media, con ligeras diferencias entre sexos que no son interpretables por el bajo número de casos disponibles. Para los bolivianos (667 alumnos, en un 98,4\% nacidos fuera de España) los niveles que se alcanzan son elevados, del 28,5\% y con fuertes desequilibrios entre sexos (36,7\% para los hombres y 19,8\% para las mujeres), valores que bajan en la generación 1,75 hasta el 16,9\%. Para los alumnos hondureños (435 estudiantes, en un $78 \%$ integrantes de la primera generación) los niveles globales de no obtención de la titulación vienen determinados por lo que sucede entre la primera generación, con elevados porcentajes del $44 \%$ entre los chicos y del $36,3 \%$ entre ellas.

Finalmente, entre los dominicanos consideramos a 513 alumnos, en un 78\% nacidos en el extranjero. Un porcentaje elevado de ellos no obtienen el título de la ESO en el año analizado, del 32,3\%, con un $40,6 \%$ de los chicos y un $25,5 \%$ de las chicas, con una distancia entre sexos notable. Estos valores, en cambio, son reducidos para las segundas generaciones, que presentan números por debajo de la media y, contrariamente a la situación anterior, con pocas diferencias entre sexos. En algunos de estos orígenes en el último curso de ESO se observa un número de chicas superior, situación que puede explicarse por una mayor preferencia para ellas en la reagrupación familiar, a expensas de una inserción más favorable en el mercado laboral.

\section{Conclusiones}

La generación de nuevas estadísticas específicas adaptadas a las transformaciones de los fenómenos sociodemográficos, especialmente cuando incorporan el aprovechamiento de los registros administrativos existentes y el enlace de estos registros con otras estadísticas de población, constituye una necesidad de primer orden para la gestión de un fenómeno tan complejo y cambiante como es la inmigración internacional. El análisis según el estatus generacional ha sido posible por un ejercicio de cruce de registros, y permite, por primera vez en Cataluña, describir el alumnado a partir de esta taxonomía, superando las visiones más clásicas que utilizaban la nacionalidad o el lugar de nacimiento. La mayoría de estadísticas sobre alumnos optan por la vía de la nacionalidad, desapareciendo de observación los alumnos que adquieren la nacionalidad española (los que llevan más tiempo o los que tienen más facilidad para ello), y visibilizando, para los nacidos en España, unos orígenes por encima de otros. De esta forma el análisis de la nacionalidad se aleja, muchas veces, de los objetivos iniciales de conocer la situación del alumnado relacionado directa o indirectamente con la migración. 
En cuanto a los dos primeros objetivos, el de la cuantificación y visibilización en la escuela, los resultados del artículo muestran un colectivo mucho mayor que el obtenido desde las perspectivas de la nacionalidad y el país de nacimiento. Además, la dinámica del propio proceso migratorio provoca que la composición de los alumnos en función de la etapa y el curso escolar sea muy diferente, y cambiante en el tiempo. El auge de las segundas generaciones, pero también de los descendientes de parejas mixtas, es creciente. Los estudiantes de origen latinoamericano quedan muchas veces invisibilizados en los datos estadísticos escolares, ya que ostentan la nacionalidad española y son nacidos en España. La utilización de la perspectiva generacional consigue visibilizar estas situaciones, y señalar su importancia. Así, y desde este punto de vista, los alumnos de origen latinoamericano son el primer grupo de alumnos relacionados con la inmigración en Cataluña, por encima de los originarios del Magreb, los cuales, por su menor acceso a la nacionalidad, son más visibles.

Respecto al tercer objetivo, el análisis de los resultados escolares, este se ve fuertemente mediatizado por dos fenómenos de elevada intensidad ocurridos recientemente. Por un lado, del acelerado boom migratorio, que conllevó una intensa presión sobre el sistema educativo con la llegada continuada de alumnos inmigrantes, en algunas escuelas con escasa preparación para ello. Por el otro, los efectos de la crisis económica, que perjudican especialmente a la población inmigrada. Las familias de algunos orígenes, como es el caso de las marroquíes, llegan a experimentar niveles de paro que superan el $50 \%$ de los activos, con valores además mantenidos durante largos periodos de tiempo. El impacto de la crisis y de las políticas de ajuste que la sucedieron se deja sentir también sobre la escuela, que sufre una reducción de recursos económicos y de personal. Las mismas trayectorias migratorias de estos alumnos han podido verse afectadas, con retornos parciales a sus países de origen. Se observa, por lo tanto, una situación excepcional, que poco tendrá que ver con la composición del alumnado en cursos venideros.

Sobre los resultados alcanzados, hemos observado como existe una elevada incidencia de la repetición de curso en secundaria, que se debe a una práctica de repetición de curso entre los alumnos nacidos fuera, y que paradójicamente es muy similar entre sexos. En cambio, los resultados escolares muestran un sesgo muy importante por sexo, favorable a las mujeres. Por otro lado, cabe destacar cómo a pesar de la proximidad idiomática, se mantienen los altos niveles de fracaso escolar entre las primeras generaciones de inmigrantes, de forma similar a otros orígenes. De esta forma, la perturbación causada por el propio proceso migratorio, más las diferencias entre sistemas educativos, serían los factores de mayor peso en la justificación de las altas tasas de fracaso.

Por otro lado, la distancia entre los resultados de la generación 1,75 y la primera generación es muy grande, lo que refuerza la importancia de acceder a la educación desde sus inicios. A diferencia del conjunto de inmigrantes, entre los latinoamericanos se constata una mejoría para las segundas generaciones, reflejo de la mayor adaptación de sus familias en la sociedad receptora. A pesar de ello, los hijos de inmigrantes latinos siguen penalizados. Estos resultados justifican la pertinencia del acercamiento generacional, y muestran una preocupante transmisión de los malos resultados escolares a los descendientes de los inmigrados.

Finalmente, el análisis específico de los cinco orígenes permite entender la amplia diversidad de situaciones existentes dentro de los alumnos de origen latinoamericano. Esto se debe tanto al calendario diferencial de las migraciones hacia España como a la diversidad de perfiles sociodemográficos implicados en la migración. 


\section{Referencias bibliográficas}

- Albaigés, B., \& Ferrer-Esteban, G. (2017). L'estat de leducació a Catalunya. Anuari 2016. Indicadors sobre lèxit educatiu a Catalunya. Barcelona: Fundació Jaume Bofill. https://www.fbofill.cat/publicacions/lestat-de-leducaciocatalunya-anuari-2016

- Álvarez Rodríguez, A. (2006). Nacionalidad de los hijos de extranjeros nacidos en España. Madrid: Ministerio de Trabajo y Asuntos Sociales.

- Álvarez Rodríguez, A. (2014). Algunos de los niños extranjeros nacidos en España son españoles. Migraciónderecho.es, 12-1-2014. http://www.migrarconderechos.es/bibliografia/hijos_extranjeros_nacidos_espana_son_ espanoles

- Aparicio, R., \& Portes, A. (2014). Crecer en España. La integración de los hijos de inmigrantes. Barcelona: Obra Social La Caixa. Colección Estudios Sociales, 38. https://obrasociallacaixa.org/documents/10280/240906/vol38_ es.pdf/1a8a03c9-e39a-4853-b15b-bb856989e7d4

- Bayona, J., Domingo, A. \& Menacho, T. (2020). Trayectorias migratorias y fracaso escolar de los alumnos inmigrados y descendientes de migrantes en Cataluña. RIS, Revista Internacional de Sociología, 78(1), e150. doi: 10.3989/ ris.2020.78.1.18.107.

- Bayona, J. \& Domingo, A. (2019). Proceso migratorio, concentración escolar y resultados académicos en Cataluña. Migraciones, 47, 3-34.

- Bayona, J., \& Domingo, A. (2018a). El fracàs escolar dels descendents de la immigració a Catalunya: més que una assignatura pendent. Perspectives Demogräfiques, 11. https://ced.uab.cat/PD/PerspectivesDemografiques_011_ CAT.pdf

- Bayona, J., \& Domingo, A. (2018b). Inmigración internacional, segundas generaciones y escuela: el caso de los alumnos de origen marroquí en Cataluña. En J.A. Rio Fernandes, J. Olcina, M.L. Fonseca et al. (coord.) XVI Coloquio Ibérico de Geografia, "La Península ibérica en el Mundo: problemas y desafíos para una intervención activa de la Geografía", Lisboa: Ed. Centro de Estudos Geográficos da Universidade de Lisboa, p. 447-455, ISBN: 978972-636-275-3.

- Bayona, J., Avila, R., \& Pujadas, I. (2018). Europa como nuevo destino de las migraciones latinoamericanas y caribeñas. Biblio 3W. Revista bibliográfica de Geografía y Ciencias Sociales, XXIII (1242). http://www.ub.edu/geocrit/ b3w-1242.pdf

- Besalú, X. (2002). Éxito y fracaso escolar en los alumnos diferentes. El alumnado de origen africano en Girona. Cuadernos de Pedagogía, 315, 72-76.

- Böhlmark, A. (2008). Age at immigration and school performance: A siblings analysis using swedish register data. Labour Economics, 15: 1366-1387.

- Bonal, X. \& Bellei, C. (2018). Introduction: the renaissance of school segregation in a context of globalization. En X. Bonal \& C. Bellei (Eds.). Understanding School Segregation: Patterns, Causes and Consequences of Spatial Inequalities in Education, 1-28. Londres: Bloomsbury Academic.

- Bonal, X., Castejón, A., Zancajo, A., \& Castel, J.L. (2015). Equitat i resultats educatius a Catalunya. Una mirada a partir de PISA 2012. Fundació Jaume Bofill. Informes breus, 60.

- Bourdieu, Pierre (1998). Capital cultural, escuela y espacio social. México: Siglo XXI.

- Cachón, L. (2003). Inmigrantes jóvenes en España. Sistema educativo y mercado de trabajo. Madrid, Instituto de la juventud (Ministerio de Trabajo y Asuntos Sociales)

- Capote, A. \& Nieto, J.A. (2017). La población extranjera en edad escolar en España: del boom de la inmigración al cambio en el ciclo migratorio. Revista de Geografía Norte Grande, 67: 93-114.

- Carrasco, S. (2003). La escolarización de los hijos e hijas de inmigrantes y de minorías étnico-culturales. Revista de Educación, 330: 99-136.

- Cebolla-Boado, H., \& Garrido, L. (2011). The impact of Immigrant Concentration in Spanish Schools: School, Class, and Composition Effects. European Sociological Review, 27(5): 606-623.

- Corak, M. (2011). Age at immigration and the education outcomes of children. Discussion Paper series, Forschungsinstitut zur Zukunft der Arbeit, 6072. Institute for the Study of Labor (IZA), Bonn.

- Departament d'Ensenyament (2012). Pla per a la reducció del fracàs escolar a Catalunya 2012-2018. Barcelona: Generalitat de Catalunya.

- Díez Nicolás, J. (2005). Las dos caras de la inmigración. Madrid: Observatorio Permanente de la Inmigración. 
- Domingo, A. (2018). Selective Migration Policies in Spain. The Case of Latin-Americans. Discussion Paper, September 2018, 18-23. (www.population-europe.eu)

- Domingo, A. (2005). Tras la retórica de la hispanidad: la migración latinoamericana en España, entre la complementariedad y la exclusión. Papers de Demografia, 254.

- Domingo, A., \& Bayona, J. (2019). Resultats escolars i immigració a Catalunya, 2011-2016: anàlisi demoespacial. Revista Catalana de Pedagogia, 15, 89-116.

- Domingo, A. \& Ortega, E. (2015). Acquisition of Nationality as Migration Policy. En A. Domingo, A. Sabater \& R. Verdugo (eds.) (2015) Demographic Analysis of Latin American Immigrants in Spain. From Boom to Bust. Nova York: Springer, 29-54.

- Fraser, N. (2017). Crisis of Care? On the Social-Reproductive Contradictions of Contemporary Capitalism. En T. Bhattacharya (ed.) Social Reproduction Theory: Remapping Class, Recentring Oppression, Stanford y Northapton: Pluto, 21-36.

- Galeano, J. \& Bayona, J. (2016). La diversidad en las metròpolis españolas. En A. Domingo (Ed.). Inmigración y

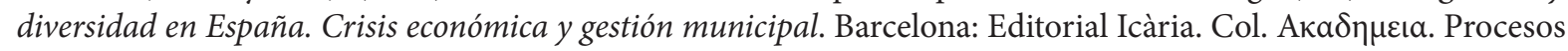
Migratorios. ISBN: 978-84-9888-726-6, 49-74.

- García Castaño, F.J., Rubio, M. \& Bouachra, O. (2008). Población inmigrante y escuela en España. Un balance de investigación. Revista de educación, 345, 23-60.

- Giorguli, S. \& Angoa, A. (2016). International migration, gender and family: A miroir from Latin America. En M.J. White (Ed.) International Handbook of Migration and Population Distribution, Springer, Dordrecht: 543-572.

- Hierro, M. (2013). Latin American migration to Spain: Main reasons and future perspectives. International Migration, 54(1): 64-83.

- Huguet, À. \& Navarro, J.L. (2006). Immigration and academic achievement: What does research show? (Introduction to the Monograph). Culture and Education, 18(2), 117-126.

- Institut d’Infància i Adolescencia de Barcelona (2019). Dades clau d’infància i adolescència a Barcelona 2018. Informe Anual. IIAB-IERMB y Ayuntamiento de Barcelona.

- Izquierdo, A., López de Lera, D. \& Martínez, R. (2002). Los preferidos del siglo XXI: la inmigración latinoamericana en España. En F.J. García-Castaño \& C. Muriel (eds.) La inmigración en España: contextos y alternativas. Vol. II. Actas del III Congreso sobre la inmigración en España (Ponencias), 232-250. Granada, España.

- OCDE (2016). PISA 2015. Resultados Clave. (https://www.oecd.org/pisa/pisa-2015-results-in-focus-ESP.pdf)

- Murillo, F.J. \& Martínez-Garrido, C. (2018). Magnitud de la Segregación escolar por nivel socioeconómico en España y sus CCAA y comparación con los países de la Unión Europea. RASE, 11(1): 37-58.

- Palaudàries, J.M. (2002). Escola i immigració estrangera a Catalunya: la integració escolar. Papers, 66, 199-213.

- Portes, A., Aparicio, R. \& Haller, W. (2016). Spanish legacies: the coming of age of the second generation. Oakland, California: University of California Press.

- Ribas-Mateos, N. (2004). How Can We Understand Immigration in Southern Europe?. Journal of Ethnic and Migration Studies, 30(6): 1045-1063

- Rumbaut, R.G. (2004). Ages, Life Stages, and Generational Cohorts: Decomposing the Immigrant First and Second Generations in the United States. International Migration Review, 38 (2): 1160-1205.

- Síndic de Greuges (2016). La segregació escolar a Catalunya (I): la gestió del procés d’admissió d’alumnat. Juliol 2016.

- Vila, I. (2006). Acerca de las relaciones entre escuela e inmigración. Revista interuniversitaria de formación del profesorado, 56, 23-44.

- Vono, D. (2010). ¿Preferidos y favorecidos? El proceso de asentamiento de la población latinoamericana en España. Tesis Doctoral, Bellaterra: Universitat Autònoma de Barcelona. 


\section{Sobre los autores}

JORDi BAYONA-I-CARRASCO

Licenciado en Geografía (UB, 1998), posgraduado en Mètodes i tècniques per a l'estudi de la població (CED, 1998) y doctor en Demografía (UAB, 2006) es Profesor Lector Serra Húnter en el Departamento de Geografía de la Universitat de Barcelona, e investigador del Centre d'Estudis Demogràfics (CED). Sus líneas de investigación se centran en el análisis demográfico de la inmigración internacional y en el estudio de las pautas de segregación y concentración en el territorio de las poblaciones inmigradas. Es miembro del GEDEM (Grupo de Estudios de Demografía y Migraciones).

Andreu Domingo i Valls

Doctor en Sociología (1997), Máster en Demografía (1989), investigador (1984) y subdirector del Centro de Estudios Demográficos (CED) desde 1997 en la Universidad Autónoma de Barcelona (UAB). Director del Grupo de Estudios de Demografía y Migraciones (GEDEM; http://gedemced.uab.cat/es), reconocido como grupo de investigación consolidado por la Generalitat de Cataluña desde 2005. Especializado en inmigración internacional y formación de familia, también se interesa por el análisis de lo imaginario social y la población. Investigador Principal del proyecto Demografía, migraciones y nuevas fronteras estadísticas: Big Data, Registros continuos de población y Registros administrativos, (CSO2017-85670-R) subvencionado por el Ministerio de Economía y Competitividad, para el período 2018-20. Entre sus últimas publicaciones destacamos, los libros Domingo, Andreu (Ed.) (2018) Demografia y Posverdad. Estereotipos, distorsiones y falsedades sobre la evolución de la población. Barcelona: Icaria y Domingo, Andreu (2018) Demografía zombi. Resilientes y redundantes en la utopía neoliberal del siglo XXI. Barcelona: Icaria, así como el artículo Domingo, Andreu (2018) "Analyzing Zombie Dystopia as neoliberal scenario: An Exercise in Emancipatory Catastrophism”. Frontiers of Sociology 3: 20. 